\title{
Nanotoxicity at the interface of stem cell niche- A researcher's responsibility
}

\author{
Debjani Nath*, Anugrah Ray and Baishakhi Bairagi \\ ${ }^{1}$ Department of Zoology, University of Kalyani, Kalyani Nadia, West Bengal, India
}

\section{Commentary}

Nanotechnology is going to occupy the twenty first century as tiny 'demons' as J C Maxwell imagined. The credit goes to the most famous and brilliant Caltech physicist Richard Phillips Feynmann who delivered an after-dinner lecture on December 29, 1959 at the annual meeting of American Physical society called "There's plenty of room at the bottom". He boldly declared that "the principle of physics, as far as I can see, do not speak against the possibility of manoeuvring things atom by atom" in fact, he saw the atomic manipulation was inevitable and "cannot be avoided" [1].

A nanometre is one billionth of a meter. In 1981 scientists achieved a new sophisticated tool to visualize a single atom with unprecedented clarity. Nanomachines can repair or rebirth the body from inside out with a great precision and skill with programmed instructions and smarter form. Cell repairing nanomachines are imagined halting aging process or reverse the process by fixing damaged DNA or other cellular materials, removing different toxins, elimination deep scars, destroying cancerous cells and fighting with countless diseases [2].

The process of synthesis of nanomaterials, their physicochemical properties have crucial effect on the biological activities of stem cell niche at the interface. Variable mechanisms of action will be implicated in the stem cell research in regenerative medicine including NP-induced cellular differentiation, modulation of different signalling molecules, and generation of toxicants like reactive oxygen species as well as transcription of different regulatory factors. A no of nanomaterials like AuNPs, AgNPs, $\mathrm{TiO}_{2}$, IONPs SPIONPs and other metallic NPs have the potential for the application of stem cells therapies in diverse diseases. Their functionalization, optimal dose and time of exposures etc. have modulating effect on differentiation. The mechanism of this modulation has not yet been characterized and not even verified through in vivo studies [3]. In general body system the adverse effect of nanomaterials depends on factors like dose and time of exposure, agglomeration, particle size, shape, crystal structure, surface properties or functionalization etc.

High biological activity, bioavailability, penetration power imposes on this material some potential tissue or organ toxicity. During the development and differentiation of any tissue/organ an orchestrated programming on DNA replication, protein distribution, cellular division to be occurred at right time is necessary. A slight change of the cellular environment can alter this process. Nanomaterials can pose the threat as toxic materials even at very low concentration and disrupt this process of development. So embryonic stem cells are being used now a days as the model for assessing toxicity as three dimensional nanotissue interactive system.
Different countries have implemented laws, regulations, rules to avoid these probable toxicities. But there is no universal protocol to regulate the toxic effect of nano formulation on organisms as well as environment. Several legislations related to ethics, safety to medical institutions and their stakeholders have been modified. USA and European union (EU) have strong governing and regulatory bodies and different guidelines to restrict the potential health risk of nanomaterials on human health and environment inside EU countries. As per the European commission " nanomaterials means a natural, incidental or manufactured materials containing particle, in an unbound state or as an aggregate or as an agglomerate, and where for $50 \%$ or more of the particles in the number size distribution, one or more external dimensions is in the size range of $1 \mathrm{~nm}$ to100 nm". Other countries like Canada Japan also have their individual rules and regulation in handling and production and application of nanomaterials to reduce toxic effects [4].

The science of nanotechnology has broader implications in the social aspect and ethical issues to be considered along with its toxicological impact. So, it is the duty of the researchers to be cautious about the terminology "nanotoxicology" as there is no definite or standardized method for testing toxicity. Toxicity depends on different issues as mentioned earlier. It is pointed to note that the commercial values of the materials are being exploited tremendously throughout the world which outpaces required research opportunities on the potential threat to the living system. "The potential danger to human beings and the environment is literally incalculable if we don't understand how nanotechnology can interact with our bodies and our world." Rep. S. Boehlert (R-NY), September 2006. The recent approach to chemical regulation is designed to accept the level of harm at the cost of the progress. This rule and regulatory approach strike the balance between public and private interest tethering economic interest and health hazards [5].

\section{References}

1. Hoet PH, Nemmar A, Nemery B (2004) Health impact of nanomaterials? Nat Biotechnol 22: 19. [Crossref]

2. Schulte PA, Salamanca-Buentello F (2006) Ethical and Scientific Issues of Nanotechnology in the Workplace. Environ Health Perspect 115: 5-12. [Crossref]

3. http://www.nanotechproject.org/

${ }^{\star}$ Correspondence to: Debjani Nath, Department of Zoology, University of Kalyani, Kalyani Nadia, West Bengal, India, Tel: (033) 2582-8750; E-mail: nath_ debjani@yahoo.co.in

Received: April 10, 2019; Accepted: April 19, 2019; Published: April 22, 2019 
Nath D (2019) Nanotoxicity at the interface of stem cell niche- A researcher's responsibility

4. Oberdorster G, Oberdorster E, Oberdorster J (2005) Nanotoxicology: An Emerging Discipline Evolving from Studies of Ultrafi ne Particles. Environ Health Perspect 113: 823-839.
5. Jeevanandam J, Barhoum A, Chan YS, Dufresne A, Danquah MK (2018) Review on nanoparticles and nanostructured materials: history, sources, toxicity and regulations. Beilstein J Nanotechnol 9: 1050-1074. [Crossref]

Copyright: (C2019 Nath D. This is an open-access article distributed under the terms of the Creative Commons Attribution License, which permits unrestricted use, distribution, and reproduction in any medium, provided the original author and source are credited. 